\title{
Valuing Coastal Habitat-Fishery Linkages under Regulated Open Access
}

\author{
Edward B. Barbier \\ Department of Economics, Colorado State University, Fort Collins, CO 80523-1771, USA; \\ Edward.barbier@colostate.edu; Tel.: +970-491-6324
}

Received: 28 February 2019; Accepted: 10 April 2019; Published: 23 April 2019

\begin{abstract}
This paper explores how regulation of an open access fishery influences the value of a coastal habitat that serves as breeding and nursery grounds. A model of the fishery supported by a coastal wetland is developed, which includes a quota rule that restricts harvest to a fixed proportion of the current stock. The model is applied to mangrove-dependent shellfish and demersal fisheries in Thailand. The value of the welfare effects associated with a change in a supporting coastal habitat is influenced significantly by whether or not the regulatory quota can adjust in response to these changes. Welfare losses are considerably higher when the quota is fixed as opposed to when it can be adjusted. With the restriction in place, effort cannot change to offset the decline in biomass, and as a result, there is a much larger fall in harvest. In addition, the welfare losses are much larger for the shellfish compared to the demersal fisheries. The analysis illustrates that imposing a regulatory rule on an open access fishery has important implications for valuing any linkage between coastal breeding and nursery habitat and a near-shore fishery.
\end{abstract}

Keywords: economic valuation; estuarine and coastal ecosystems; fishery; habitat-fishery linkages; mangroves; open access; regulated open access; quota; Thailand; wetlands

\section{Introduction}

Estuarine and coastal ecosystems worldwide provide a wide variety of important and valuable ecosystem services, from providing food and raw materials to protecting against storms, flooding and coastal erosion, to providing habitat for marine species and biodiversity [1-3]. An important benefit of many estuarine and coastal ecosystems is their role in providing breeding and nursery habitats that support near-shore fisheries. This has resulted in the development of bioeconomic models to capture this effect and value coastal-habitat linkages (see [1,4] for reviews).

Beginning with [5], studies have shown that the values estimated for improved coastal and marine habitat quality for fisheries, whether through protection of the nursery and breeding habitat service of coastal wetlands or reduction of nutrient pollution, vary with open access versus optimal management conditions [5-8]. Other studies have pointed to the influence of market structure and the regulatory environment on fisheries that are threatened by disease and other more general environmental risks $[9,10]$.

Previous work has demonstrated how open access management conditions prevalent in many fisheries influence the value imputed to coastal habitat changes [5-7]. First, if an open access fishery is more heavily exploited in the long run, the subsequent economic losses associated with the destruction of natural habitat supporting this fishery are likely to be lower. Second, the welfare effects associated with a change in a supporting coastal habitat will vary significantly with the magnitude of the elasticity of demand for the harvested fish. Thus, one should be cautious about basing coastal development decisions solely on single services such as habitat-fishery linkages when open access conditions may distort the impact of conserving coastal wetlands on increased fishery production and returns. 
In comparison, there has been a lack of analysis of how regulation of an open access fishery may influence the value imputed to coastal habitat-fishery linkages. Regulated open access refers to the imposition of biologically motivated regulations on fishers, who would otherwise enter and exit harvesting at will [11]. A number of modeling approaches have explored the economic implications for regulating an open access fishery, based on limiting the total catch through restricting entry and season length [11-14]. A common assumption is that the allowable quota on harvesting is set relative to the biomass of the fish population [13]. The models predict that regulating an open access fishery significantly impacts harvest and biomass levels, thus affecting costs and revenues. Since valuing coastal-habitat-fishery linkages is also measured through its impact on costs and economic returns, this implies that any regulation imposed on an open access fishery would influence the value considerably.

Two studies of how regulation impacts a fishery may offer some clues on what could matter in valuing coastal-habitat linkages under regulated open access [10,12]. For example, Deacon et al. [12] explore how a regulatory rule amounts to a limit on capital, but fishing firms can vary any unrestricted input, and thereby use the restricted input more intensively. In effect, this is analogous to the problem faced by a fishery when the coastal habitat supporting it declines. One input into the fishery-the biomass stock-will decrease, or essentially become 'restricted', in the long run. Although the second input, fishing effort, may vary in response to the declining stock, this could depend on whether or not the regulatory rule is fixed and restricts effort. Kennedy and Barbier [10] show that such "target flexibility" in response to environmental shocks on a regulated fishery is critical. When the shocks impact both costs and growth, harvest quotas are strongly favored over both effort quotas and taxes, but losses are reduced by harvest control mechanisms that can be adjusted in response to these shocks. As a declining coastal breeding and nursery habitat is also likely to impact costs and growth of a fishery, then valuing any changes in the habitat-fishery linkage could depend on whether or not the regulatory regime is adjusted in response to the habitat loss.

To summarize, the literature on valuing coastal-habitat-fishery linkages under open access suggests that the magnitude of the elasticity of demand is an important determinant in the welfare effects associated with a change in a supporting coastal habitat. In contrast, models on regulated open access indicate that restricting harvests so that they do not over-exploit the fish stock is likely to have implications for biomass size, costs, and returns, and thus may impact significantly the value of coastal-habitat-ishery linkages. In addition, the losses associated with any decline in coastal habitat linkages will depend on whether or not there is flexibility in adjusting the regulatory quota on harvest.

The purpose of the following paper is to explore these influences on valuing habitat-fishery linkages in a regulated open access fishery. A model of the fishery supported by a coastal wetland is developed. A quota rule is imposed to ensure that harvest must always be a fixed proportion of the current stock. The key relationships are kept analytically tractable in order to show as explicitly as possible how the regulatory restriction, compared to the elasticity of market demand, impacts the value of any change in the coastal habitat supporting the fishery. The model also indicates how the value of this habitat-fishery linkage will depend on whether or not the regulatory quota is adjusted in response to a decline in the wetland area.

Further insights into these relationships are gained by an empirical application based on mangrove-dependent shellfish and demersal fisheries in Thailand, from data and parameters estimated in [6]. Both the theoretical model and its simulation indicate that the elasticity of demand does impact the value of the welfare effects associated with a change in a supporting coastal habitat. However, this value is influenced even more by whether or not the regulatory quota can adjust in response to these changes. Welfare losses are considerably higher when the quota is fixed as opposed to when it can be adjusted. With the restriction in place, effort cannot change to offset the decline in biomass, and as a result, there is a much larger fall in harvest. In addition, the welfare losses are much more significant for the shellfish compared to the demersal fisheries. The analysis illustrates that imposing a regulatory rule on an open access fishery, such as restricting harvest to a fixed proportion of the fishing stock, has 
important implications for valuing any linkage between coastal breeding and nursery habitat and a near-shore fishery.

The next section develops the model of a regulated open access fishery with coastal-habitat linkages and applies it to the case study of mangrove-dependent fisheries in Thailand. Section 3 presents the results of simulation of these fisheries and the valuation of habitat-fishery linkages. Section 4 discusses the implications of this analysis and its results for valuing coastal habitat-fishery linkages under regulated open access. Section 5 concludes with some observations concerning policy implications and future research.

\section{Materials and Methods}

\subsection{A Regulated Open Access Fishery with Coastal-Habitat Linkages}

The starting point for the valuation approach developed in this paper is the dynamic model of coastal-habitat-fishery linkages developed in Barbier [6]. The underlying assumption of the model is that a near-shore fishery depends on a coastal wetland habitat, such as salt marsh or mangroves, as a breeding habitat and nursery. Consequently, any change in the coastal wetland habitat is likely to affect the biological growth of the fishery, which is usually modeled through some influence on carrying capacity.

Defining $X_{t}$ as the stock of fish measured in biomass units, any net change in growth of this stock over time can be represented as

$$
X_{t+1}-X_{t}=F\left(X_{t}, S_{t}\right)-h\left(X_{t}, E_{t}\right), \frac{\partial F}{\partial X_{t}^{2}}>0, \frac{\partial F}{\partial S_{t}}>0
$$

Thus, any expansion in the fish stock occurs as a result of biological growth in the current period $F\left(X_{t}, S_{t}\right)$ net of any harvesting $h\left(X_{t}, E_{t}\right)$, which is the function of the stock as well as fishing effort $E_{t}$. The influence of the wetland habitat area $S_{t}$ as a breeding ground and habitat on growth of the fish stock is assumed to be positive $\partial F / \partial S_{t}>0$, as an increase in wetland area will mean more carrying capacity for the fishery and thus greater biological growth.

As the near-shore fishery is open access, effort in the next period will adjust in response to the profits made in the current period. Letting $p\left(h_{t}\right)$ represent landed fish price per unit harvested, $w$ the unit cost of effort and $\phi>0$ the adjustment coefficient, then total effort in the fishery changes according to

$$
E_{t+1}-E_{t}=\phi\left[p\left(h_{t}\right) h\left(X_{t}, E_{t}\right)-w E_{t}\right], \frac{\partial p}{\partial h_{t}}<0
$$

Assume that biological growth is characterized by a logistic function $F\left(X_{t}, S_{t}\right)=r X_{t}\left(1-X_{t} / K\left(S_{t}\right)\right)$, and harvesting by a Schaefer production process $h_{t}=q X_{t} E_{t}$, where $q$ is the catchability coefficient, $r$ is the intrinsic growth rate and $K\left(S_{t}\right)=\alpha \ln S_{t}$ is the impact of coastal wetland area on carrying capacity $K_{t}$ of the fishery. The market demand function for harvested fish is iso-elastic, i.e., $p\left(h_{t}\right)=k h_{t}^{\eta}, \eta=1 / \varepsilon<0$. Substituting these expressions into Equations (1) and (2) yields

$$
\begin{gathered}
X_{t+1}-X_{t}=r X_{t}\left[1-\frac{X_{t}}{\alpha \ln S_{t}}\right]-h_{t}, h_{t}=q X_{t} E_{t} \\
E_{t+1}-E_{t}=\phi\left[k h_{t}^{\eta+1}-w E_{t}\right]
\end{gathered}
$$

Following Homans and Wilen [13], it is assumed that an outside regulatory body imposes a simple quota rule to ensure that current harvest does not over-exploit the stock. Here, the regulatory rule is that harvest must always be a fixed proportion $b$ of the current stock, i.e., $h_{t}=b X_{t}$. Thus, $b$ represents the quota on current harvest-stock ratio, or the regulatory quota for short. Since the Schaefer production function dictates that $h_{t}=b X_{t}=q X_{t} E_{t}$, the implication of this rule is that effort will be 
fixed at $E=b / q$. Total effort in the fishery now depends on the regulator's decision on how large a proportion $b$ of the stock can be safely fished. This can be stated in terms of the following proposition:

Proposition 1. If a regulatory rule is imposed that harvest is a fixed proportion $\mathrm{b}$ of the current stock, then total effort in the fishery is constant and determined by the size of the regulatory quota $b$, i.e., $E=b / q$.

Fixing effort in the fishery implies that Equation (4) becomes $k\left(b X_{t}\right)^{\eta+1}=w E=w b / q$. This implies that rents in the fishery will be totally dissipated. Intuitively, as total effort by all fishers is fixed, some will be able to fish enough to make profits, but others will not. The latter will leave the fishery to be replaced by those attracted by the profits, but overall effort will remain the same, and the process will repeat itself until eventually zero rents are earned throughout the fishery. The result is a unique value for fish biomass

$$
X=a b^{-\frac{\eta}{\eta+1}}, a=\left(\frac{w}{k q}\right)^{\frac{1}{\eta+1}}, \frac{d X}{d b}=-\frac{\eta}{\eta+1} a b^{-\frac{\eta}{\eta+1}-1}
$$

Thus, fish stock is also constant in the regulated fishery. Note that the impact of a change in the regulatory quota on the stock will depend on the elasticity of demand for harvested fish $\varepsilon$. That is, if demand is relatively inelastic $-1<\varepsilon<0$ (implying $\eta<-1$ ), then $d X / d b<0$. However, for elastic demand $\varepsilon<-1(-1<\eta<0)$, then $d X / d b>0$. The following proposition follows:

Proposition 2. If the market demand for fish is relatively inelastic $-1<\varepsilon<0$, then the fish stock will decrease (increase) with a positive (negative) change in the regulatory quota $b$; if the market demand is relatively elastic $\varepsilon<-1$, the fish stock will increase (decrease) with a positive (negative) change in $b$.

As fish biomass is unchanging and governed by (5), then (3) becomes

$$
r-b=\frac{r X}{\alpha \ln S_{t}}>0
$$

Since the right-hand side of Equation (6) is positive, an important implication is:

Proposition 3. The regulatory quota $\mathrm{b}$ must always be less than the intrinsic growth rate $\mathrm{r}$ of the fish stock.

Equations (5) and (6) can be solved to determine the regulatory quota $b$ that yields this equilibrium outcome for the fishery. Once $b$ is known, it is possible to find $X$ from Equation (5), $E$ from Proposition 1 , and then harvest $h$.

Valuing the impact of the change in coastal habitat area $S_{t}$ can now be determined by examining how this change influences the equilibrium harvest outcome $h$ and thus the consumer surplus for marketed fish. For example, if $h^{0}$ is the initial harvest in the fishery and $h^{1}$ is harvest after the change in coastal habitat area occurs, then the resulting change in consumer surplus $C S$ will be

$$
\Delta C S=\int_{h^{0}}^{h^{1}} p(h) d h-\left[p^{1} h^{1}-p^{0} h^{0}\right]=-\frac{\eta\left[p^{1} h^{1}-p^{0} h^{0}\right]}{\eta+1}
$$

However, the value of this habitat-fishery linkage will depend on whether or not the regulatory quota $b$ is adjusted in response to the change in $S$. 
In the case where such an adjustment occurs, then the solution for $b$ depends on the current size of the coastal habitat area, i.e., $b=b\left(S_{t}\right)$. From substituting Equations (5) in (6), one can find

$$
r-b=\frac{r a b^{-\frac{\eta}{\eta+1}}}{\alpha \ln S_{t}}, \frac{d b}{d S}=\frac{(r-b) \alpha}{S_{t}\left[\alpha \ln S_{t}-\frac{\eta}{\eta+1} r a b^{-\frac{\eta}{\eta+1}-1}\right]}
$$

As Equation (8) is currently specified, the impact of a change in $S_{t}$ on the regulatory quota $d b / d S_{t}$ is ambiguous. Once this effect is known, Propositions 1 and 2 can be invoked to determine the impacts on fishing effort $E$ and stock $X$, respectively. The ensuing changes in harvest and consumer surplus follow.

In the case where the regulatory quota $b$ does not change, fishing stock adjusts in response to the change in coastal habitat area, i.e., from Equation (6).

$$
\frac{d X}{d S}=\frac{(r-b) \alpha}{r S_{t}}>0
$$

As this impact is always positive, it leads to

Proposition 4. If the regulatory quota $\mathrm{b}$ does not adjust in response to a change in the coastal habitat area $S_{t}$, then fish stock will increase (decrease) in response to an increase (decrease) in $S_{t}$.

Because there is no adjustment to $b$, then fishing effort remains unchanged (Proposition 1). However, there is an impact on harvest, since $d h=b d X=\frac{b(r-b) \alpha}{r S} d S$. The result is a change in consumer surplus as indicated by Equation (7), which is the value attributed to the decline or increase in the coastal habitat supporting the fishery.

To summarize, the regulatory rule $h_{t}=b X_{t}$ imposed on the open access fishery with coastal habitat linkages leads to a bioeconomic equilibrium that is fully recursive. Valuing any changes in the coastal habitat supporting the fishery will depend on whether or not the regulatory quota $b$ is adjusted in response to these changes. If the regulatory quota adjusts for any change in $S_{t}$, the result will be changes in both fishing effort and stock. Although rents are still fully dissipated, the resulting change in harvest will impact consumer surplus. If $b$ does not adjust, then effort is unchanged but the stock of fish will respond to any change to coastal habitat area. Both harvest and consumer surplus are again impacted. However, these differing impacts are sufficiently important that they can affect significantly the value attributed to the coastal-habitat-fishery linkage.

\subsection{Case Study: Mangrove-Dependent Fisheries, Thailand}

The above approach for valuing coastal habitat support for a regulated fishery is illustrated through application to the mangrove-dependent demersal and shellfish fisheries in Thailand, based on data from Barbier [6].

Up to 38,000 households in around 2500 coastal communities engage in small-scale fishing activities, which are largely open access [6]. These communities are located along the Southern Gulf of Thailand and Andaman Sea (Indian Ocean) coasts. Gill nets and both motorized and non-motorized small boats are the most common form of fishing gear used by artisanal fishers. Although a license fee and permit are required for fishing in coastal waters, officials do not strictly enforce the law and users do not pay. Currently, there is no legislation for supporting community-based fishery management, and regulation of the fisheries is negligible.

Based on data from Barbier [15] that identifies which of Thailand's artisanal demersal and shellfish fisheries depend on mangroves for breeding and nurseries, Barbier [6] employs pooled time-series and cross-sectional regressions that yield the key biological parameters $(r, \alpha)$, economic parameters $(k, w, q)$ for the two fisheries. This allows determination of the key relationships in Equations (5)-(9) necessary for valuing coastal-habitat linkages in a regulated open access fishery. In addition, evidence from domestic fish markets in Thailand suggest that the demand for fish is fairly inelastic, and 
an elasticity of -0.5 is assumed for the iso-elastic market demand function. These key parameter estimates for Thailand's mangrove-dependent demersal and shellfish fisheries are summarized in Table 1. In addition, the table indicates the estimated area of mangroves along the Gulf of Thailand and Andaman Sea supporting these fisheries.

Table 1. Key parameters for mangrove-dependent fisheries, Thailand.

\begin{tabular}{ccc}
\hline Parameter & Demersal Fishery & Shellfish Fishery \\
\hline$r$ & 0.4896 & 0.2997 \\
$\alpha$ & $12,817,069$ & $24,663,448$ \\
$k$ & $1.6 \times 10^{13}$ & $6.2 \times 10^{14}$ \\
$w$ & 3415 & 113,155 \\
$q$ & 0.0002 & 0.00006 \\
$\varepsilon$ & -0.5 & -0.5 \\
$\eta$ & -2 & -2 \\
$S_{t}$ & $1672 \mathrm{~km}^{2}(1996)$ & $1672 \mathrm{~km}^{2}(1996)$ \\
\hline
\end{tabular}

Source: Barbier [6].

The parameter estimates in Table 1 are used in the model developed here to estimate the value of mangrove-fishery linkages for an open access fishery that is regulated according to the rule $h_{t}=b X_{t}$. The first step is solving conditions in Equations (5) and (6) to find the corresponding regulatory quota $b$, and then $X, E$, and $h$ for each fishery. The second step is determining the changes in consumer surplus resulting from annual average changes in mangrove deforestation, depending on whether the regulatory quota adjusts or not.

In this valuation exercise, two different calculations of annual mangrove deforestation rates are used, based on high and low estimates for Thailand over 1996 to 2004 [6]. The low estimate by the Royal Thai Forestry department is $3.44 \mathrm{~km}^{2}$; the high value by the UN Food and Agricultural Organization is $18.0 \mathrm{~km}^{2}$.

\section{Results}

\subsection{Simulation of the Regulated Mangrove-Dependent Fisheries}

Table 2 depicts the outcomes for the regulatory quota $b$, fish stock $X$, fishing effort $E$, and harvest $h$ for the mangrove-dependent demersal and fisheries, respectively, derived through applying the parameter estimates from Table 1 to the model and assuming that mangrove area remains at $1672 \mathrm{~km}^{2}$.

Table 2. Simulation results for mangrove-dependent fisheries, Thailand.

\begin{tabular}{ccc}
\hline Variable & Demersal Fishery & Shellfish Fishery \\
\hline$b$ & 0.1146 & 0.0462 \\
$X$ & $72,858,304 \mathrm{~kg}$ & $154,821,198 \mathrm{~kg}$ \\
$E$ & $561 \times 10^{3}$ hours & $766 \times 10^{3}$ hours \\
$h$ & $8,351,529 \mathrm{~kg}$ & $7,156,579 \mathrm{~kg}$ \\
$S_{t}$ & $1672 \mathrm{~km}^{2}(1996)$ & $1672 \mathrm{~km}^{2}(1996)$ \\
\hline
\end{tabular}

The model simulation applied to the demersal fishery suggests a regulatory quota of about $11.5 \%$ of fish stock. For the shellfish fishery, $b$ is much lower, around $4.6 \%$. However, because the stock of shellfish is greater than for the demersal fishery, the resulting equilibrium harvests are approximately the same. The regulated harvest $h=b X$ is around 8400 metric tons for the demersal fishery and 7200 metric tons for shellfish. 


\subsection{Valuation of Habitat-Fishery Linkages}

Table 3 depicts the resulting welfare impacts of mangrove deforestation on the demersal and shellfish fisheries, using the low and high estimates of annual deforestation. In addition, the table shows how these welfare impacts vary, depending on whether the regulatory quota adjusts or not in response to mangrove loss.

Table 3. Valuation of mangrove-fishery linkages under regulated open access, Thailand.

\begin{tabular}{ccccc}
\hline \multirow{2}{*}{ Annual Mangrove Loss } & \multicolumn{2}{c}{ Demersal Fishery } & \multicolumn{2}{c}{ Shellfish Fishery } \\
\cline { 2 - 5 } & $\mathbf{3 . 4 4} \mathbf{k m}^{\mathbf{2}}$ & $\mathbf{1 8 . 0} \mathbf{~ k m}^{\mathbf{2}}$ & $\mathbf{3 . 4 4} \mathbf{k m}^{\mathbf{2}}$ & $\mathbf{1 8 . 0} \mathbf{~ k m}^{\mathbf{2}}$ \\
\hline b constant: & & & & \\
Welfare loss $\left(\$ / \mathrm{km}^{2}\right)$ & $\$ 309$ & $\$ 309$ & $\$ 13,960$ & $\$ 13,960$ \\
Welfare loss $(\$ /$ year) & $\$ 1062$ & $\$ 5564$ & $\$ 48,031$ & $\$ 251,621$ \\
\hline b adjusts: & & & \\
Welfare loss $\left(\$ / \mathrm{km}^{2}\right)$ & $\$ 14$ & $\$ 14$ & $\$ 103$ & $\$ 103$ \\
Welfare loss $(\$ /$ year $)$ & $\$ 47$ & $\$ 245$ & $\$ 354$ & $\$ 1854$ \\
\hline
\end{tabular}

The results show that the valuation estimates of the loss in mangrove habitat-fishery support service vary considerably for the two fisheries, and depending on whether or not the regulatory quota $b$ is adjusted in response to mangrove loss. As expected, the annual welfare loss is much larger for the high versus low estimate of mangrove deforestation.

The loss in value of the mangrove-fishery linkage is much greater for the shellfish fishery as opposed to the demersal fishery. When $b$ is constant, the loss is nearly $\$ 14,000$ per $\mathrm{km}^{2}$ of mangrove decline for shellfish compared to $\$ 309$ per $\mathrm{km}^{2}$ for the demersal fishery. When $b$ can adjust, the loss is $\$ 103$ per $\mathrm{km}^{2}$ for shellfish and only $\$ 14$ for the demersal fishery. This suggests that the mangrove-habitat-fishery linkage is a more valuable service for the shellfish than the demersal fishery.

As these estimates suggest, the welfare loss for both fisheries is always higher when the regulatory quota is fixed as opposed to when it can be adjusted. When the quota is constant, effort in the fishery cannot adjust (Proposition 1), and as a result, there is a much larger fall in harvest. The corresponding loss in consumer surplus is therefore much greater (see Equation (7)). Based on the parameter estimates in Table 1, Equation (7) becomes $\triangle C S=-2 k\left[\left(h^{\prime}\right)^{-1}-h^{-1}\right], h^{\prime}=h+d h$.

Finally, at low rates of mangrove loss, the welfare decline in the habitat-fishery linkages is $\$ 1062$ per year for the demersal fishery and $\$ 48,031$ per year for the shellfish fishery. However, for the high deforestation estimate, the welfare decline is $\$ 5564$ per year for the demersal fishery and $\$ 251,621$ annually for shellfish.

\section{Discussion}

This analysis has shown that imposing a regulatory rule on an open access fishery, such as restricting harvest to a fixed proportion of the fishing stock, has important implications for valuing any linkage between coastal breeding and nursery habitat and a near-shore fishery.

First, total effort in the fishery is constant and determined by the size of the regulatory quota $b$ chosen (Proposition 1), and in turn, $b$ must always be less than the intrinsic growth rate $r$ of the fishery (Proposition 3). These two outcomes are linked. As shown in the model, the effect of restricting harvest to a fixed proportion of stock is that the fishery will converge to a bioeconomic equilibrium with constant effort and fish biomass. As $r$ represents how rapidly the fish population grows to reach carrying capacity, it must serve as an upper bound on how a large of a proportion of the stock can be harvested through the regulatory quota $b$. This condition holds for the simulation applied to mangrove-dependent fisheries in Thailand (see Tables 1 and 2). For example, in the demersal fisheries, the intrinsic growth rate is 0.49 and the corresponding equilibrium regulatory quota is estimated to be 0.11 . In the shellfish fisheries, $r$ is 0.30 and the corresponding $b$ is 0.05 . 
Second, in the regulated open access fishery the elasticity of demand also impacts the magnitude of the welfare effects associated with a change in a supporting coastal habitat. However, in the regulated fishery, the values associated with any changes in the coastal habitat supporting the fishery will depend even more on whether or not the regulatory quota $b$ is adjusted in response to these changes. As the simulation of the regulated mangrove-dependent fisheries shows, the welfare loss imputed to coastal habitat decline is always much higher when the regulatory quota is fixed opposed to when it can be adjusted.

Intuitively, this makes sense. When $b$ cannot be adjusted, effort remains fixed and so the loss of habitat area has a direct negative impact on the fish stock (see Proposition 4). Harvest must therefore fall and so must consumer surplus. However, when $b$ adjusts to accommodate for the fall in coastal habitat area, then effort must adjust also. In the mangrove-dependent fishery simulation of this paper, the correct adjustment is actually to increase $b$ in response to an increase in $S$. This allows effort to increase to offset for a decline in $X$ that must occur with the increase in the quota (see Proposition 2 ). The overall net effect is still a decline in harvest and thus consumer surplus, but not as much if the increase in $E$ did not offset some of impact on the decline in harvest from a smaller stock.

Of course, in practice it is likely to be difficult for any regulatory body to adjust its imposed fishing quota accurately in response to a change in coastal breeding and nursery habitat. Even for the simple regulated fishery model developed here, determining how to modify $b$ for a change in $S$ requires knowledge of a considerable number of key bioeconomic and habitat parameters for each fishery (see Table 1), correct estimation of key initial variables (see Table 2), and accurate determination of the relationship $b=b\left(S_{t}\right)$ such as in Equation (8).

Third, as the Thailand mangrove-dependent fishery simulation illustrates, the value of the habitat support service will vary from fishery to fishery. As the simulation shows, the value of mangroves as a breeding and nursery ground is significantly greater for shellfish compared to the demersal fishery. This suggests that, regardless of whether the fishery is regulated or open access, the type of fish populations supported by mangroves and other estuarine and coastal ecosystems will influence considerably the value of coastal-habitat-fishery linkages.

Finally, although the discussion so far has focused on the implications for managing and regulating the fishery, this analysis also demonstrates the need to manage critical estuarine and coastal ecosystems that support near-shore fisheries. As Table 2 indicates, the loss in mangroves has a significant impact on Thailand's demersal and shellfish fisheries that are essential to the livelihoods of coastal communities. Thailand's mangroves are also valuable for protection against coastal storms and for a variety of products collected by local people from the forests [6]. Given the extensive benefits of estuarine and coastal ecosystems, protection and restoration of these critical habitats are important not only for maintaining habitat-fishery linkages but also for many other important ecosystem services emanating from the coastal zone [1-3].

\section{Conclusions}

The purpose of this paper has been to explore how regulating an open access fishery may affect the value attributed to an estuarine and coastal habitat that serves as a breeding and nursery ground for the fishery. Although there is a growing number of studies that model and value this habitat-fishery linkage; to date, none have done so under conditions of regulated open access.

Models of open access fisheries indicate that the magnitude of the elasticity of demand is a significant influence on the value of any coastal-habitat linkage. However, both the model developed here for regulated open access and its application to mangrove-dependent fisheries in Thailand indicate that this value is influenced even more by whether or not the regulatory quota can adjust in response to the changes in a supporting coastal habitat. This outcome is analogous to what happens in regulated fishery when one input (capital) is restricted by a regulation, as opposed to all inputs are able to vary freely [12]. Similarly, such "target flexibility" is critical to diminishing the economic losses from environmental shocks that impact both costs and growth [10]. As more and more fisheries are regulated 
in some manner, usually through simple rules that tie harvest to 'safe' stock levels, the results of our model have important implications for both policy and future research directions.

First, even under regulated open access, the value of the coastal habitat service will vary from fishery to fishery. For example, as the Thailand case study demonstrates, the value of mangroves as a breeding and nursery ground is significantly greater for shellfish compared to the demersal fishery. Identifying which fish populations are most impacted by losses of coastal habitats remains an important policy goal, regardless of whether fisheries are open access or regulated. Similarly, identifying which of these habitats are threatened by rapid and large-scale coastal developments should also be a policy priority.

Second, the regulatory rule must be chosen carefully, and in reference to the biological and economic conditions of the fishery. In the model of this paper, the intrinsic growth rate of the fishery serves as an upper bound on the regulatory quota imposed. However, for more sophisticated models of coastal-fishery-habitat linkages with complex regulatory rules, other restrictions on the choice of the regulatory rule may apply. These need to be investigated further, especially for a regulatory fishery that is supported by estuarine and coastal ecosystems that serve as breeding and nursery grounds.

Third, although it may be difficult to adjust any regulatory restriction accurately in response to a change in coastal breeding and nursery habitat, such an adjustment could significantly mitigate the losses associated with this change. A regulatory body must consider how best to monitor its policies, to ensure that regulatory rules and measures are sufficiently flexible to accommodate the economic impacts of habitat-fishery linkages. In some instances, the body might opt for taxes and other instruments that do not severely restrict effort or harvest, as opposed to harvest or effort quotas. Choosing the correct instrument to regulate fisheries that benefit from coastal habitat-fishery linkages, and determining whether the instrument is sufficiently flexible in response to losses in coastal habitats, are important areas for future research.

Fourth, appropriate regulation of fisheries in response to loss of critical coastal breeding and nursery habitats is important, but preventing the loss of these habitats must also be recognized as an essential strategy for maintaining the long-term viability of near-shore fisheries. In recent years, linking such management approaches has become integral to ecosystem-based management of fisheries, which is starting to have impacts on fishery policy in the United States and other countries $[16,17]$.

Finally, this paper does not address how environmental uncertainty over habitat-fishery linkages may affect its value to a regulated open access fishery. The type of uncertainty and its effects can determine both the choice of regulatory instrument and whether or not it needs to be sufficiently flexible in light of the environmental risks encountered [8]. Also important is the uncertainty of the links between coastal habitats, near-shore fisheries, and more distant marine habitats, or how such habitat-fishery linkages vary across entire "seascapes" from shoreline to sea $[2,18]$. Addressing these uncertainties could be critical to future research in valuing coastal habitat-fishery linkages under regulated open access.

Funding: This research received no external funding.

Acknowledgments: I am grateful to the support and encouragement of Wally Milon and the helpful comments provided by two anonymous reviewers.

Conflicts of Interest: The author declares no conflict of interest.

\section{References}

1. Barbier, E.B. Progress and challenges in valuing coastal and marine ecosystem services. Rev. Environ. Econ. Pol. 2012, 6, 1-19. [CrossRef]

2. Drakou, E.G.; Pendleton, L.; Effron, M.; Carter Ingram, J.; Teneva, L. When ecosystems and their services are not co-located: Oceans and costs. ICES J. Mar. Sci. 2017, 74, 1531-1539. [CrossRef]

3. Turner, R.K.; Schaafsma, M. (Eds.) Coastal Zones Ecosystem Services: From Science to Values and Decision Making; Studies in Ecological Economics; Springer: New York, NY, USA, 2015; Volume 9. 
4. Foley, N.S.; Armstrong, C.W.; Kahul, V.; Mikkelsen, E.; Reithe, S. A review of bioeconomic modelling of habitat-fishery interactions. Int. J. Ecol. 2012, 861635. [CrossRef]

5. Freeman, A.M., III. Valuing environmental resources under alternative management regimes. Ecol. Econ. 1991, 3, 247-256. [CrossRef]

6. Barbier, E.B. Valuing ecosystem services as productive inputs. Econ. Pol. 2007, 22, 177-229. [CrossRef]

7. Barbier, E.B.; Strand, I.; Sathirithai, S. Do open access conditions affect the valuation of an externality? Estimating the welfare effects of mangrove-fishery linkages in Thailand. Environ. Res. Econ. 2002, 343-367. [CrossRef]

8. Smith, M.D. Generating value in habitat-dependent fisheries. The importance of fishery management institutions. Land Econ. 2007, 83, 59-73. [CrossRef]

9. Fischer, C.; Guttormsen, A.G.; Smith, M.D. Disease risk and market structure in salmon aquaculture. Water Econ. Pol. 2017, 2, 1650015. [CrossRef]

10. Kennedy, C.J.; Barbier, E.B. Renewable resource harvesting under correlated biological and economic uncertainties: Implications for optimal and second-best management. Environ. Res. Econ. 2015, 60, 371-393. [CrossRef]

11. Reimer, M.N.; Wilen, J.E. Regulated open access and regulated restricted access fisheries. Encycl. Energy Nat. Resour. Environ. Econ. 2013, 2, 215-223.

12. Deacon, R.E.; Finnoff, D.; Tschirhart, J.T. Restricted capacity and rent dissipation in a regulated open access fishery. Res. Energy Econ. 2011, 33, 366-380. [CrossRef]

13. Homans, F.R.; Wilen, J.E. A model of regulated open access resource use. J. Env. Econ. Man. 1997, 32, 1-21. [CrossRef]

14. Homans, F.R.; Wilen, J.E. Markets and rent dissipation in regulated open access fisheries. J. Env. Econ. Man. 2005, 49, 381-404. [CrossRef]

15. Barbier, E.B. Habitat-fishery linkages and mangrove loss in Thailand. Contemp. Econ. Pol. 2003, 21, 59-77. [CrossRef]

16. McLeod, K.L.; Leslie, H. (Eds.) Ecosystem-Based Management for the Oceans; Island Press: Washington, DC, USA, 2009.

17. Dolan, T.E.; Patrick, W.S.; Link, J.S. Delineating the continuum of marine ecosystem-based management: A U.S. fisheries reference point perspective. ICES J. Mar. Sci. 2016, 73, 1042-1050. [CrossRef]

18. Barbier, E.B.; Lee, K.D. Economics of the marine seascape. Int. Rev. Environ. Res. Econ. 2014, 7, 35-65. [CrossRef] 